\section{Estudo \\ Ecidebate}

em Testão

Plamejamento
Revista Estudo \& Debate, Lajeado, v. 25, n. 2, 2018. ISSN 1983-036X

DOI: http://dx.doi.org/10.22410/issn.1983-036X.v25i2a2018.1816

\title{
ANÁLISE ECONÔMICA DA PRODUÇÃO DE CANA-DE-AÇÚCAR EM DIFERENTES PACOTES TECNOLÓGICOS
}

\author{
David Ferreira Lopes Santos ${ }^{1}$, Camila Aparecida Fonseca Souza ${ }^{2}$, \\ Juliana Borba de Moraes Farinelli ${ }^{3}$, Bruna Luísa da Silva ${ }^{2}$, Kandy Horita ${ }^{2}$
}

\begin{abstract}
Resumo: A cultura da cana-de-açúcar no Brasil é uma das mais intensivas tecnologicamente em todas as etapas de produção (sementes e insumos, sistema de plantio e manejo, colheita e distribuiçáo), esta característica contribui à liderança competitiva desta cultura no cenário internacional. Por outro lado, o imperativo tecnológico requerido exige que os produtores rurais realizem elevados investimentos em máquinas e equipamentos ou tenham profícua estrutura de contratos de serviços especializados para que sua produçáo alcance igualmente produtividade e custos competitivos. Diante deste contexto, este estudo analisa a viabilidade econômica de três diferentes pacotes tecnológicos empregados em três perfis de propriedade (75, 360 e 600 ha) na regiáo de Jaboticabal-SP; estes perfis representam mais $90 \%$ dos produtores canavieiros do país que somam mais 18 mil propriedades rurais. O procedimento metodológico utilizado foi o estudo de caso múltiplos, com 3 casos, cujos dados foram explorados por meio de abordagem quantitativa e qualitativa que convergiram para a análise através do Fluxo de Caixa Descontado combinado com Análise Custo-Volume-Lucro. Os resultados reportam que a produçáo de cana-de-açúcar apresenta viabilidade econômica para os três perfis tratados, desde que exista mais de 51 ha de área para plantio e as técnicas de manejo sejam trabalhadas adequadamente. O nível de rentabilidade é restrito o que exige um planejamento técnico e financeiro detalhado para cada ciclo de produçấo. A escala é importante para a viabilidade, pois o ponto de equilíbrio é alcançado com maior folga em propriedades com maiores áreas de produção, ainda que estas demandem maiores níveis de investimento.
\end{abstract}

Palavras-chave: Administração Rural, Análise de Investimentos, Fluxo de Caixa Descontado, Produtor Rural.

\section{ECONOMIC ANALYSIS OF THE SUGARCANE PRODUCTION IN DIFFERENT TECHNOLOGICAL PROFILES}

Abstract: The sugarcane crop in Brazil is one of the most technologically intensive in all stages of production (seeds and inputs, planting and management, harvesting and distribution), this characteristic contributes

1 Pós-Doutor e Doutor em Administraçáo de Empresas pela Universidade Presbiteriana Mackenzie. Professor Assistente Doutor na Faculdade de Ciências Agrárias e Veterinárias, Universidade Estadual Paulista (UNESP).

2 Graduanda em Administração na Faculdade de Ciências Agrárias e Veterinárias, Universidade Estadual Paulista (UNESP).

3 Mestre em Administração e engenheira agronômica pela Universidade Estadual Paulista (UNESP). 
to the competitive leadership of this culture in the international scenario. On the other hand, the required technological imperative requires that rural producers make large investments in machinery and equipment or have a profitable structure of specialized service contracts so that their production also reaches productivity and competitive costs. In this context, this study analyzes the economic viability of three different technology packages used in three property profiles $(75,360$ and $600 \mathrm{ha})$ in the Jaboticabal-SP region; these profiles represent $90 \%$ more of the sugarcane producers in the country that add another 18 thousand rural properties. The methodological procedure used was the multiple case study, with 3 cases, whose data were explored through a quantitative and qualitative approach that converged to the analysis through Discounted Cash Flow combined with Cost-Volume-Profit Analysis. The results show that the production of sugarcane presents economic viability for the three treated profiles, as long as there is more than 51 ha of area for planting and the management techniques are adequately worked. The level of profitability is restricted which requires detailed technical and financial planning for each production cycle. The scale is important for the viability, because the break-even point is reached with greater slack in properties with larger areas of production, although these demand higher levels of investment

Keywords: Rural Adminstration, Investment Analysis, Discounted Cash Flow, Rural Producer.

\section{INTRODUÇÃO}

A cultura canavieira é uma das principais commodities do Brasil posicionando o país como o maior produtor mundial de cana-de-açúcar, tendo produzido na safra 2016/17736,8 milhóes de toneladas, sendo que 400,8 milhôes de toneladas correspondem à produção do Estado de Sáo Paulo (AGRIANUAL, 2017), que se destaca tanto em quantidade produzida quanto em número de produtores angariando notoriedade e impulsionando a competitividade do setor frente o comércio internacional (KOHLHEPP, 2010) (SHIKIDA, AZEVEDO e VIAN, 2011) (LIMA, TESSMER, et al., 2017).

Pode-se observar que, a cultura canavieira e de forma mais ampla toda a agricultura brasileira, a partir da década de 1990 tem se modernizado, principalmente através da implantaçáo de tecnologias desde o melhoramento genético das variedades, insumos, sistemas de manejo e máquinas e equipamentos (SHIKIDA, AZEVEDO e VIAN, 2011) (CASTRO, FRANCO e MUTTON, 2014). Os inúmeros avanços tecnológicos relativos aos equipamentos e maquinários utilizados no campo auxiliam a expansão da produção e aperfeiçoamento na renda e qualidade de vida dos agricultores atraindo para o campo, também, potenciais investidores (SOUZA, BAGOLIN e CORONA, 2010).

A evolução da cultura da cana-de-açúcar no Brasil caracteriza-se por significativas transformaçóes sociais, produtivas e inovaçôes tecnológicas em todas as etapas da atividade canavieira. Esse processo evolutivo contribuiu para a competitividade desta cultura no cenário internacional e, com efeito, sua importância para diferentes setores da economia nacional (alimentos, combustível e energia elétrica) (ROCHA, KHAN, et al., 2014) (CORTEZ, MISSIO, et al., 2016).

A notória evolução dessa cultura agrícola evidencia a necessidade de constante mudanças e melhoria ininterrupta em toda a sua cadeia produtiva, isto é, desde os fornecedores de insumos às indústrias de alimentos e distribuidoras de combustível e energia, perpassando pelo produtor rural canavieiro (BRAUNBECK e OLIVEIRA, 2006) (CORTEZ, MISSIO, et al., 2016). 
Por outro lado, os avanços tecnológicos na cultura canavieira aumentaram os desafios ao gerenciamento das propriedades rurais, em especial, na análise da viabilidade econômica destes empreendimentos (SANTOS, MENDES, et al., 2016). Este fato decorre da necessidade dos investimentos gerarem fluxos de renda compatíveis em volume e risco com a dimensão do capital requerido (BONACIM, NARDI, et al., 2013). Não obstante, produtores e administradores rurais, especialmente, de culturas perenes como a cana-deaçúcar precisam avaliar múltiplas alternativas de investimento com orçamento de capital restrito.

Para demonstrar a viabilidade econômica de uma atividade, torna-se impreterível efetuar a avaliação de investimentos, determinada através do fluxo de caixa descontado (SOUZA e CLEMENTE, 2008). Destarte, a decisão de investir em ativos fixos deve ter como fundamento a avaliação das opçóes que melhor remunerem o investimento, de modo que para este processo de decisão, há a necessidade de indicadores que balizem as alternativas, haja vista os múltiplos riscos (climáticos, agronômicos e de mercado) inerentes a cultura canavieira (BARBIERI, CARVALHO e SABBAG, 2016).

A viabilidade econômica da produção rural de cana-de-açúcar deve respeitar os postulados da teoria de investimento, deste modo, o valor gerado pelos recursos empregados deve reportar um retorno compatível com o investimento realizado e o risco assumido (LANNA e REIS, 2012). Por se tratar de uma commoditie, a escala de produção e a forma como os custos são apontados influenciam os resultados da análise de investimento, portanto, deve-se utilizar técnicas que respeitem as diferenças de tamanho das propriedades e seja evitado o uso de rateios dos custos indiretos fixos; prática largamente utilizada na agricultura para se encontrar um "custo" e "valor" médio por hectare, pois esta informação final pode enviesar os resultados para diferentes perfis de propriedade (OLIVEIRA, BORNIA, et al., 2014).

Diante desse contexto, este trabalho apresenta uma estrutura de avaliação econômica mais ampla e que pode ser estendida para diferentes perfis de propriedade, em que pese as múltiplas diferenças existentes, visando auxiliar as decisóes do produtor rural no que concerne a capacidade de retorno em cada ciclo de plantio, considerando as inúmeras incertezas inerentes as variáveis internas e externas para o setor, além do pacote tecnológico requerido para cada perfil rural.

Cabe destacar que o planejamento adequado das atividades envolvidas diretamente com a cultura da cana-de-açúcar, desde o plantio até a colheita, é primordial na sua exploração econômica, haja vista que nessa etapa são definidas as técnicas de manejo e trato cultural a serem adotadas, como insumos, máquinas, implementos, adubaçóes, escolha de variedades e pacotes tecnológicos, adicionada às incertezas e as mudanças significativas no cenário econômico, ficando a cargo dos produtores rurais o conhecimento necessário acerca de seu negócio (ANDRADE, MORAIS, et al., 2012).

Apesar da importância econômica e social do setor sucroenergético para o Brasil são poucos os estudos econômicos nesta área voltados para a produção canavieira (SANTOS, MENDES, et al., 2016), sendo que aqueles identificados na literatura ainda concentram-se somente em avaliaçóes econômicas ou financeiras segregadas ou específicas para práticas de manejo (BRAUNBECK e OLIVEIRA, 2006) (CASTRO, FRANCO e MUTTON, 
2014), variedades de cana (CAMPOS, JÚNIOR, et al., 2014) ou máquinas e equipamentos (BARROS e MILAN, 2010) (CORTEZ, MISSIO, et al., 2016).

Não se encontrou na literatura, consultando as principais bases de dados nacionais (SPELL, Scielo, Domínio Público) e internacionais (SCOPUS e WoS) documentos que avaliassem economicamente diferentes possibilidades de pacotes tecnológicos para diferentes perfis de propriedade. Considerando a existência de mais de 18 mil produtores de cana-deaçúcar no Brasil, sendo mais de $90 \%$ de pequenos e médios produtores (AGRIANUAL, 2017); entende-se que a evidenciação das condições econômicas que garantam a longevidade destas propriedades tem elevada importância econômica (impacto na balança comercial, tributos, renda e investimento) e social (geração de emprego, fixação do trabalhador e produtor no campo, distribuição de renda com a redução da necessidade de concentração de produção).

Diante lacuna de estudos empíricos que avaliem a viabilidade da produção de cana-de-açúcar em diferentes perfis de propriedade e a importância prática do tema, essa pesquisa postulou os seguintes objetivos para o trabalho: i) estruturar o orçamento de custo da produção canavieira, a partir de fluxos de caixa descontados, ii) determinar e analisar a viabilidade econômica da cultura de cana-de-açúcar na região de Jaboticabal/SP em três perfis de propriedade canavieira com estruturas tecnológicas específicas.

Desse modo, este artigo foi estruturado em mais quatro seçóes subsequentes. $\mathrm{Na}$ segunda, apresenta-se a fundamentação teórica do estudo que permitiu análise baseada na investigação empírica. A seção posterior discorre os materiais e métodos que balizaram a pesquisa e delimitaram a extensão e aplicação dos resultados. A quarta seção apresenta os resultados da pesquisa e sugere uma discussão com a literatura abordada. Por último, relatam-se as consideraçóes finais e implicaçóes deste trabalho. As referências finalizam o artigo.

\section{FUNDAMENTAÇÃO TEÓRICA}

O setor Sucroenergético brasileiro é um dos mais competitivos do mundo devido, principalmente, ao desenvolvimento da ciência e da tecnologia nacional que contribuíram para a eficiência dos sistemas de produção de cana, extração e industrialização do caldo e uso dos resíduos na adubação dos canaviais e geração de energia elétrica (SHIKIDA, AZEVEDO e VIAN, 2011) (GARCIA, LIMA e VIEIRA, 2015) (BARBIERI, CARVALHO e SABBAG, 2016).

Todavia, é comum problemas na escolha e avaliação do sistema de produção, refletindose em dificuldade para os administradores rurais, no tocante ao conhecimento relativo do desempenho da propriedade, quanto aos insumos, produtos, tratos culturais, pacotes tecnológicos, fatores indispensáveis obtidos por meio de indicadores que contribuem na análise de rentabilidade da unidade produtiva, dado que é imprescindível ter conhecimento de todos os custos e riscos envolvidos nessa operação (BONACIM, NARDI, et al., 2013) (OLIVEIRA, BORNIA, et al., 2014) (CORTEZ, MISSIO, et al., 2016).

O processo de decisão no tocante aos diferentes métodos agronômicos e tecnológicos de manejo do solo envolve as variedades de sementes e os métodos de plantio utilizados, 
tendo em vista o impacto relevante na quantidade de cana-de-açúcar produzida em um ciclo de plantio, logo, a interaçáo entre esses fatores pode ditar o sucesso ou o fracasso de todo o ciclo da cultura, haja vista que diz respeito a um investimento de longo prazo (BARROS e MILAN, 2010), em que o dispêndio de capital representa um desembolso de fundos, com o intuito de gerar retornos coerentes com a maximização da riqueza de seus proprietários e, por conseguinte criar valor econômico agregado (SANTOS, MENDES, et al., 2016).

É importante salientar que, para a sobrevivência de qualquer atividade econômica é primordial planejamento e controle sobre as culturas agrícolas produzidas e o aperfeiçoamento das atividades, tanto para fins de gestáo e obtenção de rentabilidade, como para atingir a qualidade exigida pelo mercado consumidor, que no caso da cana-de-açúcar abarca o mercado interno e externo (BIASIO, DANI, et al., 2015).

Nessa conjuntura, o administrador rural deve realizar um plano contínuo das melhores práticas produtivas, visando um gerenciamento que leve de forma equilibrada à eficiência dos recursos, aumento na produtividade da cultura e a rentabilidade, por meio da otimização dos recursos produtivos empregados na sua propriedade (BIASIO, DANI, et al., 2015). Por isso, ao investir em determinada atividade, o estudo da viabilidade econômica e financeira torna-se relevante para demonstrar o comportamento da rentabilidade, além de oportunizar uma estimativa dos impactos na gestáo da atividade canavieira, em relaçáo a possíveis acontecimentos futuros como elevação dos custos e oscilação na produção (LANNA e REIS, 2012).

O empreendimento rural engloba diversas transaçôes, dentre as quais, compra, venda, contratação de serviços, definição de pacote tecnológico, produçáo, armazenamento, arrendamento, financiamento, em razão desses fatores se faz essencial conhecer qual é o custo de produção, qual o nível de rentabilidade de cada propriedade, qual talhão contribui de forma significativa, qual o ponto de equilíbrio de cada propriedade, qual é preço de comercialização adequado, objetivando trabalhar para minimizar problemas na produção e gestão das propriedades rurais (BIASIO, DANI, et al., 2015).

Para fins fiscais, a técnica de custeio escolhida não interferirá na apuração do seu custo, depois do investimento realizado e a produção iniciada, ao passo que, para efeitos de tomada de decisáo da quantidade a ser produzida, o produtor deve utilizar parâmetros que estejam associados ao impacto dos gastos no seu fluxo de caixa e na manutençáo dos seus recursos, logo, irá demandar meios de análise que extrapole os limites dos rateios dos custos fixos por hectare e estratifique o impacto na maximização da sua renda (KOPTA, 2013).

O processo de análise econômica e financeira inclui três aspectos principais, projeção de fluxo de caixa, cálculo do custo de capital e aplicação de modelos de avaliação (BRUNI e FAMÁ, 2003). Nesse sentido, o tripé gasto, tempo e especificaçōes deve ser usufruído para que o produtor consiga organizar suas informaçôes e obter dados coerentes, dimensionando os resultados gerados na sua propriedade, os custos e a rentabilidade do empreendimento e consequentemente aferir se sua atividade é economicamente viável (VILELA, ARAÚJO, et al., 2013).

A análise de investimento reside no emprego de técnicas específicas oriundas dos princípios financeiros com o objetivo de identificar a melhor opção entre diferentes 
possibilidades de investimento (DAMODARAN, 2004) (ASSAF NETO, 2014). Tecnicamente a análise se fundamenta em equações que tenham como objetivo específico identificar e mensurar se existe ou não viabilidade em um determinado investimento, analisar o custo oportunidade, avaliar a riqueza econômica em valor presente, verificar a capacidade do projeto de gerar renda e se os fluxos de caixa do empreendimento justificam o investimento necessário para implementar o projeto (BRUNI e FAMÁ, 2003).

Partindo dessa perspectiva, notadamente os postulados da teoria de finanças devem nortear as decisões de investimento no agronegócio. Depois de relacionadas às alternativas viáveis tecnicamente é que se avaliam quais delas são atrativas financeiramente, dispondo dos indicadores gerados para assessorar o processo decisório (SOUZA e CLEMENTE, 2008) (VILELA, ARAÚJO, et al., 2013).

Nesse aspecto, alguns itens precisam ser destacados para fins de fundamentação.

i) A Margem de Contribuição (MC) é uma noção da contabilidade pertinente para avaliação da qualidade do investimento ou produto em agregar recursos ao empreendimento (MARTINS, 2010), de modo a colaborar com a superaçáo do custo fixo, em que, dissociase, o custo fixo do custo do produto, uma vez que a apuração deste custo não está associada a quantidade que será produzida, tendo em vista, que já se trata de um custo irrecuperável (MISLAIN, SANTOSA e WIDYAWATI, 2015), dada pela Fórmula 1.

\section{$M C=$ Receita líquida - Custo e Despesa Variável}

ii) O fluxo de caixa representa as entradas e saídas de recursos financeiros do negócio. Sendo assim proporciona uma visão da realidade das movimentaçôes financeiras da empresa ou propriedade rural, facilitando no processo de decisóes que envolvam a análise de investimento (ASSAF NETO, 2014).

$\mathrm{Na}$ estrutura convencional do Fluxo de Caixa Operacional para avaliaçấo de investimento, os gastos com ativos náo podem ser incorporados para não influenciar a análise da viabilidade econômica e financeira do empreendimento (DAMODARAN, 2004). Assim, o Fluxo de Caixa Operacional pode ser relacionado ao valor do investimento em capital fixo do produtor para se descobrir o Retorno sobre o Investimento (ROI Return on Investiment), de acordo com a Fórmula 2.

$$
R O I=\frac{\text { Fluxo de Caixa Operacional }}{\text { Investimento }}
$$

iii) Conhecer o ponto de equilíbrio (PEO) ou break even point permite identificar se o gestor está trabalhando com o total de receitas necessário que proporcionará equilíbrio de caixa (MARTINS, 2010), conforme a fórmula 3.

$$
P E O=\frac{\text { Custo Operacionais Fixos }}{\text { Margem de Contribuição Unitária }}
$$

A Figura 1 ilustra como é medido o desempenho da propriedade rural, evidenciando qual a quantidade de área a ser produzida para que o produtor obtenha resultado operacional e econômico positivo por meio da análise Custo-Volume-Lucro (CVL). 
Figura 1: Ilustração da análise Custo-Volume-Lucro

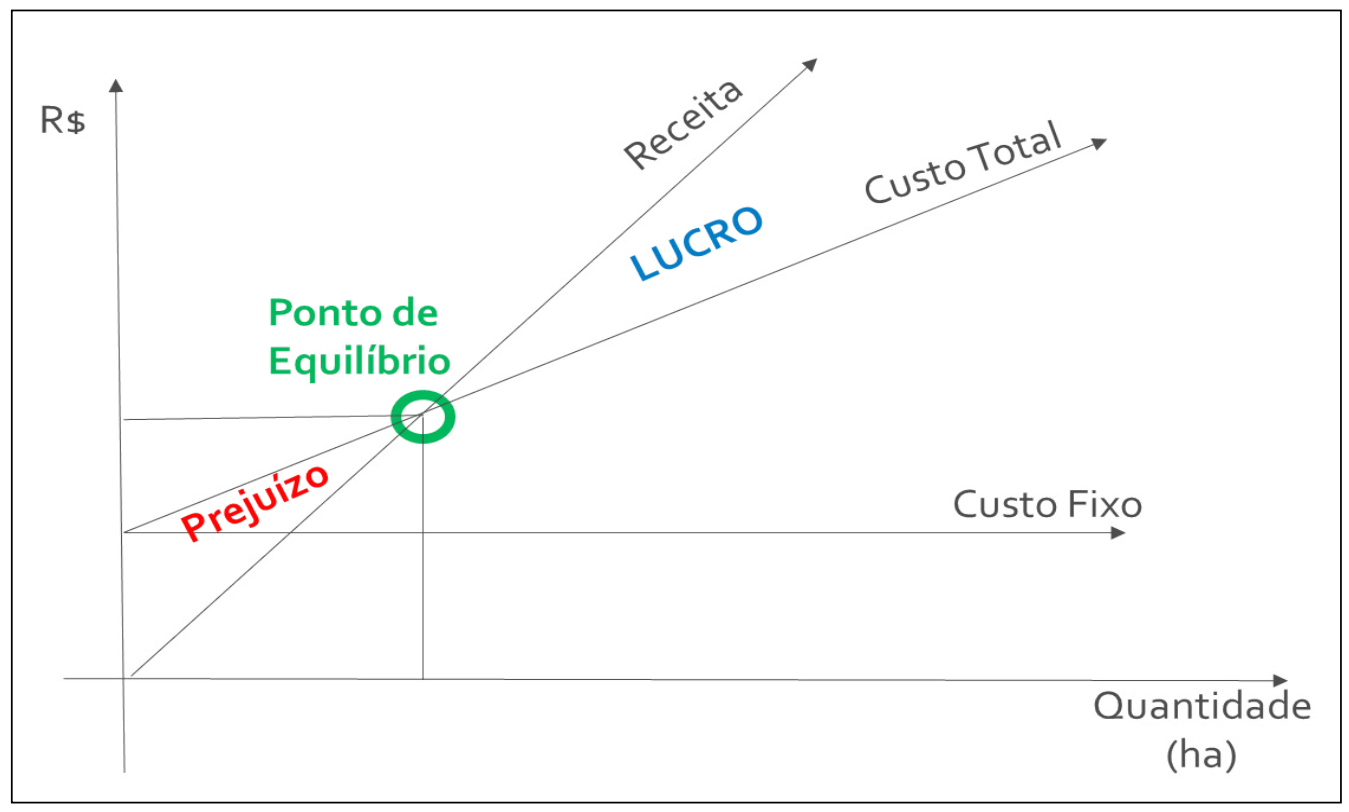

Fonte: Elaborado pelos autores.

Nesse sentido, a análise CVL em conjunto com o Fluxo de Caixa Descontado pode viabilizar parâmetros para produtor rural, no que concerne ao quanto produzir, ao impacto dos gastos no seu fluxo de caixa e na manutenção da sua riqueza, isto é, possibilita uma análise que supera os limites dos rateios dos custos fixos por hectare, além de estratificar o impacto na maximização da sua riqueza (BONACIM, NARDI, et al., 2013).

iv) A análise de investimento é usada nos diversos setores da economia, serve para medir a viabilidade dos mais diversos projetos, é a partir dela que os gestores e investidores terão informaçōes para tomar suas decisôes (SOUZA e CLEMENTE, 2008). No que diz respeito a agricultura, mais especificadamente a cana-de-açúcar, este método apresenta particularidades específicas em relação a outros setores, como reduzida liquidez dos investimentos em capital fixo, maior exposição aos riscos exógenos (clima, praga, órgáos reguladores, liberação de mercados, câmbio, etc.) e limitaçóes técnicas para constituição de carteira de produção (DACORSO, LEITE e MOLINA-PALMA, 2007) (BARROS e MILAN, 2010).

Todavia, essas diferenças na agricultura não eliminam a essência da avaliação de investimento, qual seja, o somatório dos fluxos de caixas operacionais futuros deve sempre ser superior ao valor do investimento. Dessa forma, para uma análise robusta dos investimentos, existem algumas técnicas como o Valor Presente Líquido (VPL), Taxa Interna de Retorno (TIR), Payback e Índice de Lucratividade (IL) sendo que para tanto, deve-se realizar o Fluxo de Caixa Descontado que incorpora a avaliaçáo dos investimentos baseada nos fluxos de caixa de natureza operacional, o risco é agregado na avaliação econômica dos 
investimentos e o valor presente do ativo com base na taxa de desconto (GITMAN, 1987) (DAMODARAN, 2004) (ASSAF NETO, 2014).

Nesse artigo, utilizou-se como técnica de análise dos investimentos o VPL que é encontrado subtraindo-se o investimento inicial de um projeto do valor presente de suas entradas de caixa, descontadas à taxa de custo de capital da empresa (GITMAN, 1987), em que o investidor realizará o projeto, se e somente se, o VPL for positivo (DAMODARAN, 2004), a Fórmula 4 ilustra o cálculo VPL.

$$
V P L=\sum_{t=1}^{t=n} \frac{F C L_{t}}{(1+i)^{n}}
$$

Adicionalmente ao uso do VPL, este estudo vislumbra a possibilidade de agregar a Análise de Custo-Volume-Lucro ao modelo como forma de identificar o ponto de equilíbrio para cada cenário, a partir do Valor Presente de cada conta, assim, tem-se o ponto de equilíbrio não apenas para um ano, mas para todo o investimento (SANTOS, MENDES, et al., 2016).

\section{MATERIAL E MÉTODOS}

A estratégia utilizada foi baseada em estudos de caso múltiplos, isto é, três casos em propriedades distintas, haja vista que este é um instrumento de investigação empírico que busca estudar um fenômeno dentro da sua realidade, a partir da descrição das situaçóes cotidianas e contexto em que se desenvolve a pesquisa (GIL, 2008). Em adição, o estudo de caso viabiliza o levantamento de informaçóes com maior detalhamento, mediante a interação, entre o pesquisador e o contexto estudado (MARCONI e LAKATOS, 2003), favorecendo o processo de coleta de materiais, tendo em vista que muitas propriedades não tem totalmente articulado seus dados operacionais, financeiros e econômicos.

Nesse sentido, a partir da Associação dos Fornecedores de Cana-de-açúcar de Guariba - SOCICANA, ocorreu a seleção das propriedades por meio da sua base de dados, em que verificou-se os perfis modais de produtores considerando os mais de 1700 associados. Assim, os produtores entrevistados representam três perfis distintos de propriedades na regiáo com base no seu tamanho $(75,360$ e 600 hectares) e estrutura tecnológica utilizada.

Sabe-se que cada propriedade é uma realidade e por isso os resultados não podem ser generalizados, com tudo a utilização de amostras modais permite avaliaçóes comparativas no limite das suas diferenças e ainda a abordagem baseada em fluxo de caixa pode orientar cada produtor à construção do seu próprio fluxo de caixa.

Os dados foram coletados em fontes primárias e secundárias, como segue: i) relatórios em planilhas eletrônicas quanto aos gastos de quatro propriedades no tocante à aquisição de insumos e máquinas; ii) entrevistas com os produtores da região de Jaboticabal; iii) contratos de financiamento; iv) verificação dos documentos fiscais, contábeis, e comerciais; v) visitas as áreas de cultivo para investigação das práticas operacionais e tratos culturais nos talhóes; vi) tomada de preço junto a fornecedores de insumos e bens de capital na região; vii) consulta de preço de terra no IEA; e viii) definição do pacote tecnológico pertinente com profissionais da principal associação de produtores da região e acadêmicos. 
Para tal, foram realizadas visitas in loco nas propriedades para coleta de informaçóes, que ocorreu entre os meses de Abril/2017 e Maio/2017, computando três visitas, uma em cada propriedade, nas quais foram realizadas entrevistas com os proprietários e administradores rurais por tempos variados, de acordo com a gama de informaçóes e nível de controle documental de cada produtor, para posterior leitura e análise de planilhas fornecidas pelos mesmos.

No interesse de triangular as informações com os produtores, os resultados levantados pelos mesmos foram discutidos com técnico (Engenheiro Agrônomo) da SOCICANA, cuja experiência no setor é maior que 35 anos como e com pesquisadores na área de mecanização agrícola, essa estratégia teve como objetivo validar esse perfil tecnológico como "representativo" para a região.

Este estudo tem natureza aplicada com abordagem qualitativa e quantitativa, na medida em que compreende tanto a necessidade da interpretação das informaçóes referentes a entidade pesquisada, como utilização de técnicas quantitativas para coleta e tratamentos dos resultados (GIL, 2008).

O método baseou-se no Fluxo de Caixa Descontado (FCD) que traz a valor presente o fluxo de renda gerado pelo investimento, a partir de uma Taxa de Mínima de Atratividade (TMA) (DAMODARAN, 2004). A Tabela 1 discrimina os itens utilizados para estimar a TMA, sendo esta utilizada para todas as análises de investimento.

Tabela 1. Premissas para a definição da Taxa Mínima de Atratividade

\begin{tabular}{l|c}
\hline Itens & Valores \\
\hline CDI real (a.a.) (junho/2017) & $6,10 \%$ \\
\hline Beta & 0,22 \\
\hline Prêmio de mercado (a.a.) & $6,00 \%$ \\
\hline Custo econômico do produtor & $7,43 \%$ \\
\hline Financiamento para ativos Fixos a.a. (BNDES) & $6,46 \%$ \\
\hline Financiamento do custeio da produçáo a.a. (Crédito Agrícola) & $7,22 \%$ \\
\hline
\end{tabular}

Fonte: Elaboração própria, a partir dos dados da pesquisa.

Pontua-se que o beta foi calculado como coeficiente da reta de regressão entre as variaçóes mensais dos preços de mercado do Açúcar Total Recuperável (ATR) com a variação do Ibovespa dos últimos 36 meses, caracterizando assim uma proxy para o risco sistemático da cultura de cana para o período $\mathrm{O}$ prêmio de mercado foi utilizado o prêmio histórico para o mercado brasileiro (ASSAF NETO, 2014). Diante dessas informaçóes o custo econômico do produtor foi estimado em 7,43\% a.a.. Nas propriedades modais investigadas a estrutura de capital média que financia o investimento é $80 \%$ capital próprio, $20 \%$ capital de terceiros, sendo $50 \%$ deste em financiamento de máquinas e equipamentos e $10 \%$ do financiamento para custeio da produção. Por isso, o custo médio ponderado de capital foi determinado em 7,31\% a TMA. 


\subsection{Premissas da Receita}

Para determinação da receita considerou-se a variação estimada da produtividade e o preço do quilograma do Açúcar Total Recuperável por tonelada de cana (kg de ATR/ ton). No ano de 2017 o valor do ATR foi de $\mathrm{R} \$ 0,60 / \mathrm{kg}$, valor da terra $\mathrm{R} \$ 120.000,00$ o alqueire (2,42 ha) e Custo de Colheita, Carregamento e Transporte (CCT) R \$ 21,00/ tonelada. Para determinar as receitas futuras foram construídos três cenários para o preço do ATR, considerando a volatilidade da série histórica do ATR para a região de Jaboticabal-SP.

Ressalta-se que a quantidade de ATR pode ser mantida para todos os cortes, contanto que leve em consideração todas as premissas necessárias para sua definição, assim, nesse estudo estipulou-se o valor de 138, conforme a Tabela 2 .

Tabela 2. Quantidade produzida de cana/ha (TCH) e açúcar total recuperável (ATR)

\begin{tabular}{l|c|c|c|c|c|c}
\hline & $\mathbf{1}^{\circ}$ Corte & $\mathbf{2}^{\circ}$ Corte & $\mathbf{3}^{\circ}$ Corte & $\mathbf{4}^{\circ}$ Corte & $5^{\circ}$ Corte & $\mathbf{6}^{\circ}$ Corte \\
\hline TCH/ha & 140 & 112 & 102 & 92 & 82 & 72 \\
\hline ATR/ha & 138 & 138 & 138 & 138 & 138 & 138 \\
\hline
\end{tabular}

Fonte: Elaboração própria, a partir dos dados da pesquisa.

Quanto aos valores do TCH, para o primeiro corte estes foram determinados a partir de dados reais da propriedade somados a consulta em anuários, referentes à safra 2016/17, para os cortes subsequentes considerou-se a média das produtividades anteriores do talhão, bem como a redução da produtividade que ocorre naturalmente com o envelhecimento da planta.

\subsection{Premissas dos Custos Variáveis e Fixos}

Os custos variáveis para cada perfil de propriedade encontram-se na Tabela 3, separados por etapas, em que conservação do solo abarca construção de curvas, terraceamento, construção ou manutenção do carreador e auxiliar de topografia; preparado do solo engloba calagem, carregamento de calcário, gessagem, subsolagem, aplicação de diferentes herbicidas, transporte da calda, além de grades niveladoras, intermediária e aradora; por fim, plantio que se refere as mudas, fertilizantes, inseticidas, fungicidas, regulador de crescimento e quebra lombo, bem como as práticas corriqueiras do manejo da cultura.

Tabela 3. Composição dos custos variáveis

\begin{tabular}{l|c|c|c|c|c|c}
\hline \multirow{2}{*}{ Custos Variáveis de Plantio/ha } & \multicolumn{2}{|c|}{75 ha } & \multicolumn{2}{c|}{360 ha } & \multicolumn{2}{c}{ 600ha } \\
\cline { 2 - 7 } & $\mathrm{R} \$$ & $\%$ & $\mathrm{R} \$$ & $\%$ & $\mathrm{R} \$$ & $\%$ \\
\hline Conservação do Solo & 386 & 5,3 & 386 & 5 & 386 & 7,3 \\
\hline Preparo de Solo & 1.209 & 16,8 & 1.227 & 16 & 1.227 & 23 \\
\hline Plantio & 5.619 & 78 & 6.118 & 79 & 3.706 & 69,7 \\
\hline $\begin{array}{l}\text { Total dos Custos Variáveis de } \\
\text { Plantio }\end{array}$ & 7.213 & 100 & 7.731 & 100 & 5.318 & 100 \\
\hline
\end{tabular}

Fonte: Elaboração própria, a partir dos dados da pesquisa. 
O CCT também integra os custos variáveis, sua determinação está atrelada a distância geográfica da propriedade com a usina, juntamente com o preço do ATR. Para este artigo o CCT fixado é de R \$21,00/tonelada de cana, sendo este o valor médio na regiáo estudada.

$\mathrm{Na}$ etapa de conservação do solo não há diferença no custo por hectare, pois as atividades inerentes não diferem nas exigências de recursos tecnológicos e de mão-de-obra entre os diferentes tamanhos de propriedade.

Cabe destacar, que para os dois primeiros perfis, de 75 e 360 ha, o plantio foi realizado de modo terceirizado, ao passo que para a propriedade de 600 ha, o método foi plantio próprio, esse diferença no modo de plantio explica a diminuição do custo com plantio para a propriedade de 600 ha, dado que no plantio próprio não está incluso a mão-de-obra na apuração dos custos variáveis e sim nos custos fixos, pois para este perfil de propriedade os funcionários possuem contratos de trabalho fixo para todo o ano.

A Tabela 4 ilustra a composição utilizada para determinação do custo fixo das propriedades, é de extrema importância se atentar para esses gastos, uma vez que serão mantidos para todos os cortes da cana, logo, esse valor existirá havendo ou não produção.

Tabela 4. Custos fixos ano/safra 2016/2017

\begin{tabular}{l|c|c|c}
\hline CUSTOS FIXOS (Valores anuais) & $\mathbf{7 5 h a}$ & $\mathbf{3 6 0 h a}$ & $\mathbf{6 0 0 h a}$ \\
\hline Manutenção Tratores e Implementos & 8.561 & 26.448 & 48.848 \\
\hline Funcionários & 113.802 & 208.387 & 318.654 \\
\hline Seguros & 3.275 & 6.127 & 8.344 \\
\hline Tributos e Taxas & 1.339 & 3.505 & 5.329 \\
\hline TOTAL Custos Fixos & $\mathbf{1 2 6 . 9 7 8}$ & $\mathbf{2 4 4 . 4 6 7}$ & $\mathbf{3 8 1 . 1 7 5}$ \\
\hline
\end{tabular}

Fonte: Elaboração própria, a partir dos dados da pesquisa.

Em virtude de se tratar de uma commoditie a escala é de extrema importância para aumentar a rentabilidade da atividade canavieira em funçáo da minimização do custo fixo (funcionários fixos, seguros, manutenção de máquinas e implementos, além de taxas e tributos) e melhor utilização dos investimentos (terra, benfeitorias, máquinas e implementos). O comportamento dos custos fixos totais em valores anuais para cada perfil de propriedade é evidenciado na Figura 2. 
Figura 2: Custos fixos anuais das propriedades com 75, 360 e 600 hectares

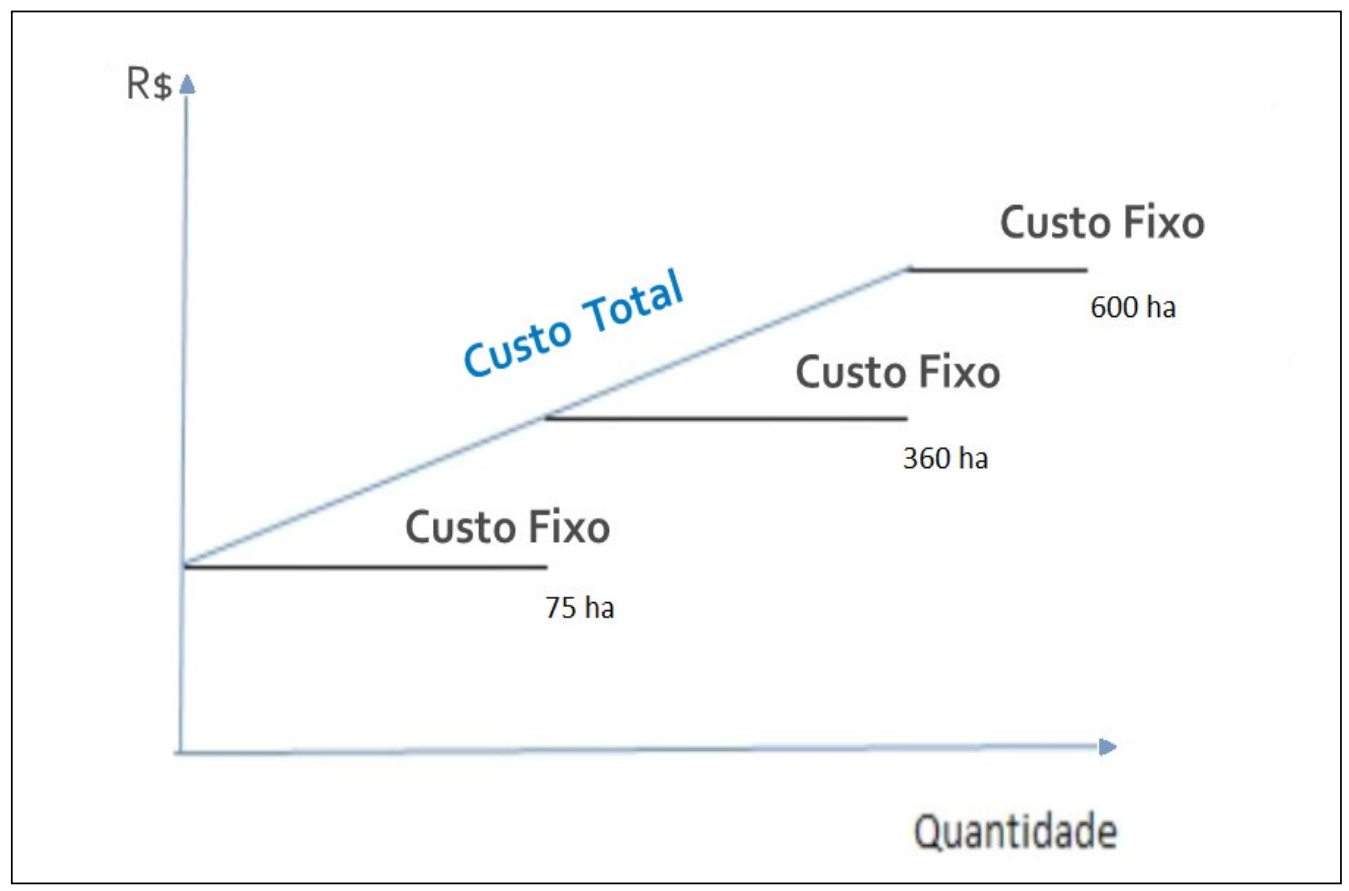

Fonte: Elaborado pelos autores.

\subsection{Premissas dos Investimentos}

A Tabela 5 elenca o pacote tecnológico adotado para cada perfil de propriedade e suas respectivas quantidades.

Tabela 5. Pacote tecnológico, quantidade utilizada e valor do investimento para cada perfil de propriedade

\begin{tabular}{l|c|c|c}
\hline Tratores e Implementos & $\mathbf{7 5 h a}$ & $\mathbf{3 6 0 h a}$ & $\mathbf{6 0 0 h a}$ \\
\hline Trator $180 \mathrm{cv}$ & - & 1 & 2 \\
\hline Trator $150 \mathrm{cv}$ & - & - & 1 \\
\hline Trator $120 \mathrm{cv}$ & - & - & 1 \\
\hline Trator 110 & 1 & 2 & 2 \\
\hline Trator 105 & 1 & - & - \\
\hline Trator 80 & - & 2 & 2 \\
\hline Trator 65 & 1 & - & - \\
\hline Distribuidora de Calcário & 1 & 2 & - \\
\hline Distribuidora de Calcário e Fertilizante & - & - & 2 \\
\hline Distribuidora de Tolete (plantadora) & - & - & 1 \\
\hline
\end{tabular}




\begin{tabular}{l|c|c|c}
\hline Tratores e Implementos & 75ha & 360ha & 600ha \\
\hline Transbordo & - & - & 1 \\
\hline Carreta & 1 & 1 & 2 \\
\hline Tanque & 1 & 2 & 2 \\
\hline Sulcador & - & - & 1 \\
\hline Cobridor & - & - & 1 \\
\hline Grade Aradora & - & 1 & 1 \\
\hline Grade Niveladora & 1 & 1 & 1 \\
\hline Grade Intermediária & 1 & 1 & 2 \\
\hline Subsolador & 1 & 1 & 1 \\
\hline Cultivador/Adubadora & 1 & 2 & 2 \\
\hline Aplicador Sphenophorus & 1 & 1 & 2 \\
\hline Pulverizador de barras & 1 & 2 & 3 \\
\hline Plaina & 1 & 1 & 1 \\
\hline Guincho 3 pontos & 1 & 1 & 1 \\
\hline Pá carregadeira & 1 & 1 & 2 \\
\hline Carro Fiat Strada & 1 & 1 & 1 \\
\hline Kombi Volkswagen & - & 1 & 1 \\
\hline Caminháo Munk & 5.296 .708 & 23.130 .132 & 38.580 .745 \\
\hline Valor do Investimento (valores em R\$) & & & 1 \\
\hline Fon Elaba pora & & 1 & 1 \\
\hline
\end{tabular}

Fonte: Elaboração própria, a partir dos dados da pesquisa.

Notadamente, a propriedade com 75 ha dispóe de um pacote tecnológico mais enxuto, isto é, tratores de menores potência e implementos menores, combinado ao plantio manual (semi-mecanizado) terceirizado, à medida que a propriedade com 360 ha usufrui de um pacote tecnológico com tratores de maior potência e implementos maiores se comparada a propriedade de 75 ha, juntamente com o plantio através de distribuidora de toletes terceirizado, por fim, a propriedade de 600 ha, faz uso de pacote tecnológico robusto, com maior número de tratores, implementos e equipamentos de plantio, haja vista que realiza plantio próprio através de distribuidora de toletes.

Partindo dessa perspectiva, os investimentos aumentam com o tamanho da propriedade em razão da ampliação do pacote tecnológico e uso de equipamentos mais potentes, além do valor total da terra.

\section{RESULTADOS E ANÁLISES}

A análise de viabilidade econômica se faz importante devido ao fato de ela medir se um investimento trará retorno ou não para o investidor. Com isso, o empreendedor consegue direcionar seu esforço e dinheiro para projetos promissores, assim como, corrigir problemas inerentes a técnicas de manejo, sistema de produção e tesouraria da sua propriedade (SANTOS, MENDES, et al., 2016). 
Nesse sentido, investigar a viabilidade econômica da cultura de cana-de-açúcar é de suma importância, pois, ao contrário de outras grandes culturas do país como milho e soja, a cana-de-açúcar tem a possibilidade de ciclos de colheita que extrapolem 6 anos, de modo que os gastos inerentes a plantação e seus resultados devem ser contrastados em todos os ciclos (SOARES, BIANCO, et al., 2016).

Em geral, a literatura recomenda 6 ciclos de colheita, para maximizar a produtividade dos canaviais, dada as alteraçóes tecnológicas no processo de plantio e colheita da cana-deaçúcar, assim como, as mudanças legais nas áreas ambientais e trabalhistas que trouxeram uma nova realidade para o processo agrícola nos últimos anos (PEREIRA, JÚNIOR, et al., 2015) (SOARES, BIANCO, et al., 2016).

Cabe frisar a necessidade de rotação de culturas na atividade agrícola em função da manutenção do solo, como um processo natural preservação de nutrientes que promove a recuperação das condiçôes físicas e biológicas da terra, além de contribuir para minimização de pragas (TAVARES e ZONTA, 2010) (BARROS e MILAN, 2010). Para promover essa questão, os produtores rurais dividem a área em "talhóes" de modo que a rotação da cultura seja viável e resulte em menor impacto no fluxo de caixa da propriedade.

Assim, nesse estudo a avaliação da viabilidade considerou o ciclo de produção de 6 anos, em que se empregou a combinaçáo das técnicas de Fluxo de Caixa Descontado, a partir de uma taxa de mínima de atratividade definida com o valor real de 7,3\% ao ano. Todos os valores referem-se ao primeiro semestre de 2017. Utilizou-se também a análise Custo-Volume-Lucro, permitindo assim, combinar a análise econômica com a análise financeira, dado que se trata de uma ferramenta de gestấo que contribui com os processos de planejamento, gerenciamento e controle da propriedade, influenciando de maneira acentuada a tomada de decisão (SOUZA, SCHNORR e FERREIRA, 2011) (BONACIM, NARDI, et al., 2013).

Neste método, o valor de um determinado ativo está associado a sua capacidade de geraçáo de caixa, a o seu risco inerente e a vida útil do projeto (DAMODARAN, 2004). Para tanto, calculou-se o fluxo de caixa livre para o investidor no decorrer da vida útil do investimento, de forma que, os valores de cada período são descontados à TMA que foi calculada pelo Custo Médio Ponderado de Capital (CMPC), conforme a Tabela 1 (PEREIRA, JÚNIOR, et al., 2015), isto é, o fluxo de caixa é transcrito em Valor Presente, de modo a auxiliar o investidor a compreender o princípio do valor do dinheiro no tempo, além de mensurar o quanto o investimento, naquele momento, é vantajoso.

A Tabela 6 apresenta as demonstraçóes do fluxo de caixa detalhado para uma propriedade com 75 ha, em que cada talháo representa 12,5 hectares. 
Tabela 6. Fluxo de caixa da propriedade com 75 hectares (valores em R $\$$ )

\begin{tabular}{|c|c|c|c|c|c|c|c|c|}
\hline & $\begin{array}{c}\text { Valor } \\
\text { Presente }\end{array}$ & $\mathbf{0}$ & 1 & 2 & 3 & 4 & 5 & 6 \\
\hline Receita Bruta & 2.438 .671 & - & 476.100 & 505.080 & 515.430 & 525.780 & 536.130 & 546.480 \\
\hline Dedução CCT & 610.010 & - & 101.850 & 138.600 & 130.725 & 133.350 & 135.975 & 138.600 \\
\hline Dedução F R & 42.059 & - & 8.608 & 8.429 & 8.848 & 9.026 & 9.204 & 9.381 \\
\hline Receita Líquida & 1.786 .602 & - & 365.642 & 358.051 & 375.857 & 383.404 & 390.951 & 398.499 \\
\hline $\mathrm{CV}$ & 849.004 & 112.161 & 178.898 & 178.430 & 180.682 & 178.129 & 183.347 & 5.625 \\
\hline $\mathrm{MC}$ & 937.599 & -112.161 & 186.744 & 179.621 & 195.175 & 205.275 & 207.604 & 392.874 \\
\hline $\mathrm{CF}$ & 644.785 & 126.978 & 126.978 & 126.978 & 126.978 & 126.978 & 126.978 & - \\
\hline EBTIDA & 292.813 & -239.139 & 59.767 & 52.643 & 68.198 & 78.298 & 80.627 & 392.874 \\
\hline Depreciação & 531.311 & - & 147.348 & 147.348 & 147.348 & 147.348 & 36.783 & 12.933 \\
\hline Resultados Op. & -238.498 & -239.139 & -87.581 & -94.705 & -79.150 & -69.050 & 43.844 & 379.941 \\
\hline IR $(24 \%)$ & 72.770 & - & - & - & - & - & 10.522 & 99.180 \\
\hline $\begin{array}{l}\text { Resultados } \\
\text { Líquidos }\end{array}$ & -311.268 & -239.139 & -87.581 & -94.705 & -79.150 & -69.050 & 33.321 & 280.761 \\
\hline Depreciação & 531.311 & - & 147.348 & 147.348 & 147.348 & 147.348 & 36.783 & 12.933 \\
\hline $\mathrm{FCO}$ & 220.044 & -239.139 & 59.767 & 52.643 & 68.198 & 78.298 & 70.104 & 293.694 \\
\hline Custo Econômico & 1.349 .538 & 235.245 & 235.245 & 235.245 & 235.245 & 235.245 & 235.245 & 235.245 \\
\hline FCE & -1.129 .495 & -474.384 & 175.478 & -182.602 & -167.048 & -156.947 & -165.141 & 58.449 \\
\hline $\begin{array}{l}\text { FCD com custo } \\
\text { econômico }\end{array}$ & -1.129 .495 & 474.384 & -163.687 & -158.886 & -135.585 & -118.827 & -116.630 & 38.505 \\
\hline
\end{tabular}

Notas: CCT - Custo de Carregamento e Transporte; FR - Fundo Rural; CV - Custo Variável; MC - Margem de Contribuição; CF- Custo Fixo; FCO - Fluxo de Caixa Operacional; FCE - Fluxo de Caixa Econômico; FCD - Fluxo de Caixa Descontado.

Fonte: Elaboração própria, a partir dos dados da pesquisa.

Conforme a Tabela 6, percebe-se um aumento da receita líquida ao longo dos ciclos, margem de contribuição positiva e superior ao custo variável total, condição vital para qualquer atividade, apresentando também margem de contribuição com valores superiores aos custos fixos, fatores que contribuem para o Fluxo de Caixa Operacional positivo para a propriedade, ainda que o custo econômico seja elevado.

Assim, pode-se dizer que a produção canavieira para o produtor com o perfil de propriedade de 75 ha é rentável quanto aos custos variáveis e fixos, apresentando ponto de equilíbrio inferior à área plantada, sendo alcançado em 51 ha, além de rentabilidade do investimento (ROI) positiva em $0,9 \%$.

Não obstante, como o ROI de $0,9 \%$ é inferior ao retorno esperado pelo proprietário definido em 7,3\%, o investimento não remunera o capital desejado pelo produtor, o que resulta um custo de oportunidade mais elevado que o valor presente do FCO, derivando em um fluxo de caixa descontado econômico negativo.

A Tabela 7 retrata as demonstraçóes do fluxo de caixa detalhado para uma propriedade com 360 ha, em que cada talhão representa 60 hectares. 
Tabela 7. Fluxo de caixa da propriedade com 360 hectares (valores em R $\$$ )

\begin{tabular}{l|c|c|c|c|c|c|c|c}
\hline & $\begin{array}{c}\text { Valor } \\
\text { Presente }\end{array}$ & $\mathbf{0}$ & $\mathbf{1}$ & $\mathbf{2}$ & $\mathbf{3}$ & $\mathbf{4}$ & $\mathbf{5}$ & $\mathbf{6}$ \\
\hline Receita Bruta & 11.705 .622 & - & 2.285 .280 & 2.424 .384 & 2.474 .064 & 2.523 .744 & 2.573 .424 & 2.623 .104 \\
\hline Dedução CCT & 2.968 .817 & - & 579.600 & 614.880 & 627.480 & 640.080 & 652.680 & 665.280 \\
\hline Dedução F R & 200.947 & - & 39.231 & 41.619 & 42.471 & 43.324 & 44.177 & 45.030 \\
\hline Receita Líquida & 8.535 .858 & - & 1.666 .449 & 1.767 .885 & 1.804 .113 & 1.840 .340 & 1.876 .567 & 1.912 .794 \\
\hline CV & 4.205 .191 & 538.374 & 889.763 & 898.325 & 886.071 & 911.120 & 889.763 & 27.000 \\
\hline MC & 4.330 .667 & -538.374 & 776.686 & 869.560 & 918.042 & 929.219 & 986.803 & 1.885 .794 \\
\hline CF & 1.241 .390 & 244.467 & 244.467 & 244.467 & 244.467 & 244.467 & 244.467 & - \\
\hline EBTIDA & 3.089 .277 & -782.841 & 532.219 & 625.093 & 673.575 & 684.752 & 742.337 & 1.885 .794 \\
\hline Depreciação & 1.063 .223 & - & 296.820 & 296.820 & 296.820 & 296.820 & 62.505 & 27.765 \\
\hline Resultados Op. & 2.026 .055 & -782.841 & 235.399 & 328.273 & 376.755 & 387.933 & 679.832 & 1.858 .029 \\
\hline IR (24\%) & 818.949 & - & 56.496 & 81.613 & 98.097 & 101.897 & 201.143 & 601.730 \\
\hline Resultado Líquido & 1.207 .106 & -782.841 & 178.903 & 246.660 & 278.658 & 286.036 & 478.689 & 1.256 .299 \\
\hline Depreciação & 1.063 .223 & - & 296.820 & 296.820 & 296.820 & 296.820 & 62.505 & 27.765 \\
\hline FCO & 2.270 .329 & -782.841 & 475.723 & 543.480 & 575.478 & 582.855 & 541.194 & 1.284 .064 \\
\hline Custo Econômico & 5.893 .282 & 1.027 .289 & 1.027 .289 & 1.027 .289 & 1.027 .289 & 1.027 .289 & 1.027 .289 & 1.027 .289 \\
\hline FCE & -3.622 .954 & -1.810 .131 & -551.566 & -483.809 & -451.811 & -444.434 & -486.095 & 256.775 \\
\hline FCD com custo & -3.622 .954 & -1.810 .131 & -514.503 & -420.974 & -366.716 & -336.488 & -343.301 & 169.160 \\
\hline econômico & - & - & -196 & \\
\hline
\end{tabular}

Notas: CCT - Custo de Carregamento e Transporte; FR - Fundo Rural; CV - Custo Variável; MC - Margem de Contribuição; CF- Custo Fixo; FCO - Fluxo de Caixa Operacional; FCE - Fluxo de Caixa Econômico; FCD - Fluxo de Caixa Descontado.

Fonte: Elaboração própria, a partir dos dados da pesquisa.

Verifica-se que a produçáo canavieira para esse perfil de produtor é rentável, haja vista que apresenta margem de contribuição superior aos custos variáveis e fixos, rentabilidade do investimento (ROI) positiva em 2,1\%, ponto de equilíbrio alcançado em 103 ha, apresentando maior fôlego ao produtor, além do fluxo de caixa operacional positivo.

Todavia, como o ROI de $2,1 \%$ é inferior ao retorno esperado pelo proprietário definido em 7,3\%, o investimento não remunera o capital esperado pelo produtor, o que gera um custo de oportunidade mais elevado que o valor presente do FCO, refletindo em um fluxo de caixa descontado econômico negativo.

A Tabela 8 exibe as demonstraçóes do fluxo de caixa detalhado para uma propriedade com 600 ha, em que cada talhão representa 100 hectares. 
Tabela 8. Fluxo de caixa da propriedade com 600 hectares (valores em $\mathrm{R} \$$ )

\begin{tabular}{|c|c|c|c|c|c|c|c|c|}
\hline & $\begin{array}{c}\text { Valor } \\
\text { Presente }\end{array}$ & $\mathbf{0}$ & 1 & 2 & 3 & 4 & 5 & 6 \\
\hline Receita Bruta & 19.509 .370 & - & 3.808 .800 & 4.040 .640 & 4.123 .440 & 4.206 .240 & 4.289 .040 & 4.371 .840 \\
\hline Dedução CCT & 4.948 .029 & - & 966.000 & 1.024 .800 & 1.045 .800 & 1.066 .800 & 1.087 .800 & 1.108 .800 \\
\hline Dedução FR & 334.911 & - & 65.384 & 69.364 & 70.786 & 72.207 & 73.629 & 75.050 \\
\hline Receita Líquida & 14.226 .430 & - & 2.777 .416 & 2.946 .476 & 3.006 .854 & 3.067 .233 & 3.127 .611 & 3.187 .990 \\
\hline $\mathrm{CV}$ & 6.024 .807 & 897.291 & 1.241 .679 & 1.255 .949 & 1.235 .525 & 1.277 .274 & 1.241 .679 & 45.000 \\
\hline MC & 8.201 .624 & -897.291 & 1.535 .737 & 1.690 .527 & 1.771 .329 & 1.789 .959 & 1.885 .932 & 3.142 .990 \\
\hline $\mathrm{CF}$ & 1.935 .587 & 381.175 & 381.175 & 381.175 & 381.175 & 381.175 & 381.175 & - \\
\hline EBTIDA & 6.266 .037 & -1.278 .466 & 1.154 .561 & 1.309 .351 & 1.390 .154 & 1.408 .784 & 1.504 .757 & 3.142 .990 \\
\hline Depreciação & 1.815 .115 & - & 504.742 & 504.742 & 504.742 & 504.742 & 117.427 & 46.057 \\
\hline Resultados Op. & 4.450 .922 & -1.278 .466 & 649.819 & 804.609 & 885.412 & 904.041 & 1.387 .330 & 3.096 .933 \\
\hline IR (24\%) & 1.805 .890 & - & 190.939 & 243.567 & 271.040 & 277.374 & 441.692 & 1.022 .957 \\
\hline $\begin{array}{l}\text { Resultado } \\
\text { Líquido }\end{array}$ & 2.645 .032 & -1.278 .466 & 458.881 & 561.042 & 614.372 & 626.667 & 945.638 & 2.073 .976 \\
\hline Depreciação & 1.815 .115 & - & 504.742 & 504.742 & 504.742 & 504.742 & 117.427 & 46.057 \\
\hline $\mathrm{FCO}$ & 4.460 .147 & -1.278 .466 & 963.623 & 1.065 .784 & 1.119 .114 & 1.131 .410 & 1.063 .065 & 2.120 .033 \\
\hline $\begin{array}{l}\text { Custo } \\
\text { Econômico }\end{array}$ & 9.829 .915 & 1.713 .504 & 1.713 .504 & 1.713 .504 & 1.713 .504 & 1.713 .504 & 1.713 .504 & 1.713 .504 \\
\hline FCE & -5.369 .768 & -2.991 .970 & -749.882 & -647.720 & -594.390 & -582.095 & -650.439 & 406.528 \\
\hline $\begin{array}{l}\text { FCD com custo } \\
\text { econômico }\end{array}$ & -5.369 .768 & -2.991 .970 & -699.493 & -563.597 & -482.441 & -440.714 & -459.368 & 267.815 \\
\hline
\end{tabular}

Notas: CCT - Custo de Carregamento e Transporte; FR - Fundo Rural; CV - Custo Variável; MC - Margem de Contribuição; CF- Custo Fixo; FCO - Fluxo de Caixa Operacional; FCE - Fluxo de Caixa Econômico; FCD - Fluxo de Caixa Descontado.

Fonte: Elaboração própria, a partir dos dados da pesquisa.

Cabe destacar que nos três perfis de propriedade a margem de contribuição é positiva, indicando o montante que resta da receita após a dedução de seus custos e despesas variáveis, isto é, demonstra como cada ciclo colabora para primeiro amortizar os custos fixos e, depois, constituir o lucro esperado pelo empreendedor (MARTINS, 2010).

Contudo, como o ROI de 2,4\% é inferior ao retorno esperado pelo proprietário definido em 7,3\%, o investimento não remunera o capital esperado pelo produtor, o que ocasiona um custo de oportunidade mais elevado que o valor presente do FCO, resultando em um fluxo de caixa descontado econômico negativo.

Assinala-se que o sistema de tributação previsto é a apuração pelo lucro real, assim, outras modalidades como lucro presumido ou simples nacional, podem gerar diferentes resultados.

O custo econômico inviabiliza conceitualmente toda a atividade, porém sua determinação é controversa e a análise pela rentabilidade deve direcionar as decisóes dos produtores. Nessa linha, as rentabilidades para as propriedades são inferiores as taxas de 
juros praticadas pelos programas de apoio ao produtor, o que a médio e longo prazo se reflete em problemas de alavancagem financeira.

A Tabela 9 apresenta os resultados obtidos para os perfis avaliados de forma estratificada. Nota-se que o aumento do ROI ocorre com a maior escala da produçáo.

Tabela 9. Resultados Financeiros e Econômicos da produção de Cana-de-açúcar para a regiâo de Jaboticabal-SP

\begin{tabular}{c|c|c|c|c|c}
\hline $\begin{array}{c}\text { Perfil da } \\
\text { propriedade }\end{array}$ & Investimento & $\begin{array}{c}\text { FCO } \\
\text { Anualizado }\end{array}$ & ROI & PEO & CF / ha \\
\hline $75 \mathrm{ha}$ & 5.296 .708 & 54.794 & $0,9 \%$ & 51 & 1.693 \\
\hline $360 \mathrm{ha}$ & 23.130 .132 & 459.993 & $2,1 \%$ & 103 & 679 \\
\hline $600 \mathrm{ha}$ & 38.580 .745 & 883.508 & $2,4 \%$ & 141 & 635 \\
\hline
\end{tabular}

Notas: FCO - Fluxo de Caixa Operacional; ROI - Retorno sobre o Investimento; PEO - Ponto de Equilíbrio Operacional em hectares; CF - Custo Fixo.

Fonte: Elaboração própria, a partir dos dados da pesquisa.

Os resultados demostram que os três perfis de propriedade $(75,350$ e 600 ha) com seus respectivos pacotes tecnológicos, apresentam viabilidade financeira e econômica como pode ser observado pelo fluxo de caixa operacional e retorno do investimento (ROI) que exibem resultados positivos, além do ponto de equilíbrio ser inferior à área plantada de cada propriedade.

Vale enfatizar que o ponto de equilíbrio, também chamado de break even point, ocorre quando o custo total iguala a receita, isto é, a partir desse ponto cada unidade vendida terá sua margem de contribuição que antes unicamente contribuía para cobrir custos e despesas fixas, passando a gerar lucratividade, auxiliando o produtor no tocante a quantidade que precisa ser vendida para não obter prejuízo e cobrir todos os custos (MARTINS, 2010) (SOUZA, SCHNORR e FERREIRA, 2011).

As diferenças nos custos fixos demonstram a importância da análise estratificada por perfil de propriedade e o uso do custeio direto, em que somente as partes variáveis dos custos são consideradas na apropriação (MARTINS, 2010) (ANDRADE, MORAIS, et al., 2012).

Neste panorama, um ponto que deve ser atentado quanto aos custos fixos e sua participação no resultado dos fluxos de caixa, é que quando observado de modo geral, sem considerar a estratificaçáo por hectare, nota-se que conforme aumenta o tamanho da propriedade, maiores são os custos fixos totais incorridos, conforme as Tabelas 6,7 e 8 , no entanto, se observados os resultados obtidos para o custo fixo por hectare, esses diminuem com o aumento no tamanho da propriedade, de acordo com a Tabela 9, daí a relevância da escala para a análise de custos.

Quanto aos investimentos, percebe-se seu aumento de acordo com o tamanho da propriedade, o que é compreensível, dado que quanto maior a quantidade de hectares, maior é a demanda por máquinas, equipamentos e implementos para executar os tratos culturais 
e práticas de manejos, e que o produtor apenas deve ser atentar, uma vez que investir e ou vender ativos fixos são decisóes estratégicas que ser analisadas pelo administrador rural.

Salienta-se que os resultados obtidos evidenciam o diferencial desse trabalho, que procurou aplicar a teoria citada aos casos analisados, reforçando a premissa de não utilizar os rateios para definição dos custos, diferente do que é comumente visto na literatura e anuários (OLIVEIRA, BORNIA, et al., 2014) (MOREIRA e BONIZIO, 2012) (AGRIANUAL, 2017), dado que se levou em consideração o volume do capital fixo e seu notório impacto no fluxo de caixa do produtor, bem como a importância de realizar análise de investimento nas propriedades rurais, uma vez que a viabilidade do investimento está associada à escala de produção.

A construção dos resultados através da utilização da estrutura estratificada do fluxo de caixa moldada mediante análise Custo-Volume-Lucro demonstra que é possível e necessário à segregação dos custos fixos e variáveis para efeitos de tomada de decisão e controle das atividades realizadas.

\section{CONSIDERAÇÓES FINAIS}

A produção de cana-de-açúcar apresenta viabilidade econômica para pequenos, médios e grandes produtores na região de Jaboticabal, desde que exista mais de 51 ha de área para plantio e as técnicas de manejo sejam trabalhadas adequadamente. Contudo, o nível de rentabilidade é restrito o que exige um planejamento técnico e financeiro detalhado para cada ciclo de produção. A escala é importante para a viabilidade, pois o ponto de equilíbrio é alcançado com maior folga em propriedades com maiores áreas de produção.

Os custos fixos impactam significativamente os critérios para tomada de decisão e por isso devem ser segregados, para que a margem de contribuição assinale a alternativa ou condição mínima de investimento. $\mathrm{O}$ rateio de custos fixos pode distorcer a visão do produtor diante de sua propriedade e motivar uma tomada de decisão equivocada. Nessa linha, a utilização do custo total por hectare pode induzir o produtor a erros, como não considerar a escala de produçáo, levando em conta meramente a diferença entre receita e custo para apurar sua lucratividade e ou em caso de resultados negativos a opção do não plantio ou redução da quantidade, o que pode resultar em fluxo de caixa ainda mais desfavorável, em razão dos custos irrecuperáveis e custos fixos da propriedade.

O trabalho abrangeu duas importantes áreas do conhecimento, administração e ciências agrárias, em que se buscou retratar a realidade do empresário rural canavieiro, uma vez que foi modelado a partir de dados reais e estrutura tecnológica das propriedades estudadas, além de apresentar ferramentas que se adequam à realidade do produtor e o auxiliam no processo decisório. Os dados e resultados possuem uma grande representatividade uma vez que o local de execução do experimento, a Região de Jaboticabal, é a maior produtora de cana-de-açúcar do Estado de São Paulo e este o maior produtor de cana do Brasil.

Lembra-se que, enquanto estudo de caso, o trabalho tem restriçóes para com extrapolações e limitaçóes com o levantamento e análise de dados que são condicionadas por fatores chaves, como o preço de insumos, clima, dólar e preço da commoditie. Assim, os resultados demonstrados não devem ser generalizados, cabe a cada produtor junto a sua 
realidade econômica e agrícola a avaliação das condições de viabilidade da sua produção, utilizando como modelo o perfil da propriedade que melhor se enquadra, somados aos anuários como finalidade de obter parâmetro e fontes de informaçóes complementares para a compreensão de sua realidade.

\section{REFERÊNCIAS}

AGRIANUAL. Anuário da Agricultura Brasileira. São Paulo: Informa economics, 2017.

ANDRADE, M. G. F. D. et al. Controle de custos na agricultura: um estudo sobre a rentabilidade na cultura da soja. Custos e @gronegócio Online, v. 8, n. 3, 2012, p. 24-45.

ASSAF NETO, A. Finanças Comporativas e Valor. 8. ed. São Paulo: Atlas, 2014.

BARBIERI, R. S.; CARVALHO, J. B. D.; SABBAG, O. J. Análise de viabilidade econômica de um confinamento de bovinos de corte. Interaçóes, v. 17, n. 3, 2016, p. 357-369.

BARROS, F. F.; MILAN, M. Qualidade operacional do plantio de cana-de-açúcar. Bragantia, v. 69, n. 1, 2010, p. 221-229;

BIASIO, R. et al. Determinação do custo e da rentabilidade na cultura do morango em uma pequena propriedade agrícola situada em Flores da Cunha/RS. Custos e @ gronegócio Online, v. 11, n. 1, 2015, p. 161-183.

BONACIM, C. A. G. et al. Projetos de investimentos em agronegócios: análise custovolume-lucro considerando incerteza e risco. Custos e @gronegócio Online, v. 9, n. 3, 2013, p. 27-48;

BRAUNBECK, O. A.; OLIVEIRA, J. T. A. Colheita de cana-de-açúcar com auxílio mecânico. Revista Engenharia Agrícola, v. 26, n. 1, 2006, p. 300-308.

BRUNI, A. L.; FAMÁ, R. As Decisóes de Investimentos 3. ed. São Paulo: Atlas, 2003.

CAMPOS, P. F. et al. Variedades de cana-de-açúcar submetidas à irrigação suplementar no cerrado Goiano. Revista Engenharia Agrícola, v.34, n. 6, 2014, p. 1139-1149.

CASTRO, S. G. Q. D.; FRANCO, H. C. J.; MUTTON, M. Â. Harvest managements and cultural practices in sugarcane. Revista Brasileira de Zootecnia, v. 38, n. 1, 2014, p. 299-306.

CORTEZ, J. W. et al. Quality of sugarcane mechanized planting. Journal of the Brazilian Association of Agricultural, v. 36, n. 6, 2016, p. 1136-1144. 
DACORSO, A. L. R.; LEITE, K. C. T.; MOLINA-PALMA, M. A. Inovação e competitividade: um estudo sobre a capacidade de inovar do pequeno produtor de rosas de Barbacena (MG). Estudos Sociedade e Agricultura, v. 15, n. 1, 2007, p. 160-190.

DAMODARAN, A. Finanças corporativas: teoria e prática. Porto Alegre: Bookman, 2004.

GARCIA, J. R.; LIMA, D. A. L. L.; VIEIRA, A. C. P. A nova configuração da estrutura produtiva do setor sucroenergético brasileiro: panorama e perspectivas. Revista de Economia Contemporânea, v. 19, n. 1, 2015, p. 162-184.

GIL, A. C. Métodos e Técnicas de Pesquisa Social. 6. ed. São Paulo: Atlas, 2008.

GITMAN, L. J. Principios da Administração Financeira. 3. ed. São Paulo: Harbra, 1987.

KOHLHEPP, G. Análise da situação da produção de etanol e biodiesel no Brasil. Estudos Avançados, n. 24, v. 68, 2010, p. 223-253.

KOPTA, D. Impact of the structure of agricultural production to the fi nancial health of farms. Acta Universitatis Agriculturae et Silviculturae Mendelianae Brunensis, v, 61, 2013, p. 2317-2325.

LANNA, G. B. M.; REIS, R. P. Influência da mecanização da colheita na viabilidade econômico-financeira da cafeitucultura do sul de Minas Gerias. Coffee Science, v. 7, n. 2, 2012, p. 110-121.

LIMA, R. B. et al. Sugarcane cells as origin of acid beverage floc in cane sugar. Food Chemistry, v. 237, 2017, p. 1004-1011.

MARCONI, M. D. A.; LAKATOS, E. M. Fundamentos de Metodologia Científica. 5. ed. São Paulo: Altas, 2003.

MARTINS, E. Contabilidade de Custos. São Paulo: Atlas, 2010.

MISLAIN; SANTOSA; WIDYAWATI. Study of Techno-Economic of Corn Sheller Type MPJ-01-TEP-2014 Design of Study Program Agricultural Engineering, University of Andalas. International Journal on Advanced Science, Engineering and Information Technology, v. 5, n. 1, 2015, p. 23-26.

MOREIRA, M. G.; BONIZIO, R. C. Análise comparativa dos custos de cana-de-açúcar: produção independente x usina de açúcar e álcool. Custos e @gronegócio Online, v. 8, n. 2, 2012, p. 84-99. 
OLIVEIRA, T. B. A. et al. Análise de custos e eficiência de fazendas produtoras de canade-açúcar por meio da análise envoltória de dados. Custos e @gronegócio Online, v. 10, n. 1, 2014, p. 228-252.

PEREIRA, R. M. et al. Viabilidade econômica da irrigação de cana-de-açúcar no cerrado Brasileiro. Irriga \& Inovagri, Edição Especial, 2015, p. 149-157.

ROCHA, L. A. et al. A importância da política de inovação no desenvolvimento da agricultura brasileira. Estudos Sociedade e Agricultura, v. 22, n. 1, 2014, p. 224-246.

RODRIGUES FILHO, S.; JULIANI, A. J. Sustentabilidade da produção de etanol de canade-açúcar no Estado de São Paulo. Estudos Avançados, v. 27, n. 78, 2013, p. 195-212.

SANTOS, D. F. L. et al. Viabilidade econômica e financeira na produção de cana-deaçúcar em pequenas propriedades rurais. Custos e @gronegócio Online, v. 12, n. 4, 2016, p. 222-254.

SHIKIDA, P. F. A.; AZEVEDO, P. F. D.; VIAN, C. E. D. F. Desafios da Agroindústria Canavieira no Brasil Pós-desregulamentação: uma análise das capacidades tecnológicas.

Revista de Economia e Sociologia Rural, v. 49, n. 3, 2011, p. 599-628.

SOARES, M. B. B. et al. Weed Community in a Raw Sugarcane Renovation Area Submitted to Different Soil Managements. Planta Daninha, v. 34, n. 1, 2016, p. 91-98.

SOUZA, A.; CLEMENTE, A. Decisóes Financeiras e Análise de Investimentos Fundamentos, Técnicas e Aplicaçóes. 6. ed. São Paulo: Altas, 2008.

SOUZA, M. A. D.; SCHNORR, C.; FERREIRA, F. B. Análise das Relaçóes CustoVolume-Lucro como Instrumento Gerencial: Um Estudo Multicaso em Indústrias de Grande Porte do Rio Grande do Sul. Revista de Contabilidade e Organizaçóes, v. 5, n. 12, 2011, p. 109-134.

SOUZA, O. T. D.; BAGOLIN, I. P.; CORONA, H. M. P. A publicização do campo: políticas agrícolas e de desenvolvimento frente às múltiplas funçóes do espaço rural. Estudos Sociedade e Agricultura, v. 18, n. 1, 2010, p. 193-219.

TAVARES, O. C. H.; ZONTA, E. L. E. E. Crescimento e produtividade da cana planta cultivada em diferentes sistemas de preparo do solo e de colheita. Acta Scientiarum Agronomy, v. 32, n. 61, 2010, p. 61-68.

VILELA, M. C. et al. Análise da viabilidade econômico-financeira de projeto de piscicultura em tanques escavados. Custos e @gronegócio Online, v. 9, n. 3, 2013, p. 154-173. 